\title{
外延晶体硅薄膜太阳电池的器件模拟及性能优化 的研究
}

\author{
艾斌", 张勇慧，邓幼俊，沈辉 \\ 中山大学光电材料与技术国家重点实验室, 广东省光伏技术重点实验室, 广州 510006 \\ *E-mail: stsab@mail.sysu.edu.cn
}

收稿日期: 2011-08-03; 接受日期: 2012-06-18

国家自然科学基金(批准号: 50802118)、广东省科技计划(批准号: 2011A032304001, 2010B090400020)和中央高校基本研究经费青年教 师培育项目(批准号: 2011300003161469)资助

\begin{abstract}
摘要由于晶体硅薄膜太阳电池兼有晶体硅太阳电池高效、性能稳定和薄膜电池低成 本的优点, 是最有可能取代现有晶体硅太阳电池技术的下一代薄膜电池技术. 本文利用 PC1D 软件对外延晶体硅薄膜太阳电池进行了器件模拟. 为了使模拟更接近真实的情况, 我们采用了更符合实际情况的器件结构和参数设置. 在此基础上, 全面系统地研究了背 表面场(back surface field, BSF)层、基区和发射区参数、晶体硅活性层电学质量、电池表 面钝化情况、电池内部复合情况和 pn 结漏电情况等对外延晶体硅薄膜太阳电池光电性能 的影响. 在影响外延晶体硅薄膜太阳电池效率的众多因素中, 辨认出对电池效率影响幅 度最大的 3 个参数依次是基区少子扩散长度、二极管暗饱和电流和正表面复合速度. 通 过模拟还发现，基区不是越厚越好，基区厚度的选择必须要考虑基区少子扩散长度的值. 当基区少子扩散长度较小时, 基区的最佳厚度应小于或等于基区少子扩散长度; 当基区 少子扩散长度较大时, 基区少子扩散长度应至少是最佳基区厚度的 2 倍. 此外, 本文不但 对模拟结果的现象进行了描述, 还深化解释了其变化的物理机制. 由于外延晶体硅薄膜 太阳电池在器件结构上与晶体硅太阳电池具有很大的相似性, 所以本文的结论在某种程 度上对晶体硅太阳电池特别是当下研究最热门的薄硅片太阳电池也是适用的.
\end{abstract}

关键词

太阳电池

晶体硅薄膜太阳电池 器件模拟

PC1D 模拟
由于器件模拟具有大幅消减研发成本和缩短研 究周期的巨大优势, 它已成为太阳电池研发过程中 不可或缺的重要技术手段. 随着计算机技术的飞速 发展, 近年来太阳电池的器件模拟正朝着对电池进 行全尺寸模拟的方向发展. 就太阳电池的三维数值 模拟而言, 目前人们需要结合使用光学模拟软件(譬 如 Sunrays 等人)、半导体器件三维模拟软件(譬如
Sentaurus 等人)和电路模拟软件(譬如 Pspice 等人)来 实现 ${ }^{[1]}$. 具体地说, 使用光学模拟软件模拟太阳电池 的光吸收率和表面反射率; 使用三维器件模拟软件 模拟太阳电池的 $I-V$ 特性曲线; 使用电路模拟软件模 拟栅线电极造成的欧姆损失以及整个太阳电池的 $I-V$ 输出特性.

由于太阳电池的三维数值模拟需要使用多种软

英文版发表信息： Ai B, Zhang Y H, Deng Y J, et al. Study on device simulation and performance optimization of the epitaxial crystalline silicon thin film solar cell. Sci China Tech Sci, 2012, 55: 3187-3199, doi: 10.1007/s11431-012-5004-5 
件以及专用的服务器, 模拟的成本很高, 而且模拟过 程也十分复杂, 所需的工作量也很大, 因此, 目前国 际上从事太阳电池三维数值模拟研究的人并不多, 绝大多数研究者主要还是通过一维器件模拟软件(譬 如 PC1D) 对器件结构和参数进行优化 ${ }^{[2 \sim 8]}$. 事实上, 任何太阳电池都是三维器件, 严格来说, 一维模拟软 件只能对一个方向上物理特性有变化的、平面结构的 太阳电池进行精确的数值模拟. 但是, 如果器件的三 维结构所带来的效应可以忽略, 那么该器件显然可 以利用一维模拟软件进行模拟. 实际上, 即使器件的 三维结构所带来的效应不能忽略, 也可使用“等价器 件结构”或“有效参数”等转换或近似方法结合一维模 拟软件对它进行器件模拟 ${ }^{[4 \sim 6]}$.

PC1D 可能是光伏行业内最著名、最通用的太阳 电池一维模拟软件 ${ }^{[7 \sim 9]}$. 该软件最初是一个与 IBM 个 人电脑兼容的电脑应用程序, 利用有限元方法来求 解太阳电池中电子和空穴在准一维传输时所满足的 完全耦合非线性方程组. 经过 20 多年的不断完善, 特别是借助对高效单晶硅太阳电池的数值模拟研究, PC1D 建立起一套非常成熟的物理模型和算法 ${ }^{[9 \sim 13]}$. 正因为如此, PC1D 对晶体硅太阳电池性能的模拟结 果具有极高的准确性, 这是其他光伏器件模拟软件 所无法比拟的.

由于晶体硅薄膜太阳电池兼有晶体硅电池(高 效、长寿命、性能稳定、材料丰富无毒等)和薄膜电 池(成本低廉, 预计只有晶体硅电池的 1/5 到 1/2)的优 点, 近 10 多年来一直都是国际光伏学界的研究热

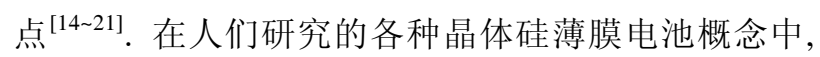
在低成本、重掺杂的晶体硅祄底(譬如颗粒硅带)上直 接外延晶体硅薄膜太阳电池可能是最简单的技术路 线. 基于器件结构的简单性和与传统晶体硅电池技 术的兼容性, 开展外延晶体硅薄膜太阳电池的研究 在经济上是值得的 ${ }^{[19-21]}$.

Faller ${ }^{[20]}$ 最早将 PC1D 应用于外延晶体硅薄膜太 阳电池的优化设计, 并重点研究了电池效率与基区 厚度、掺杂浓度和基区少子扩散长度的关系. 但是, 由于参数设置过于理想化 (譬如假定祄底与 BSF 层界 面的复合速度仅有 $500 \mathrm{~cm} / \mathrm{s}$ 等), 造成模拟结果的可 信度大打折扣. 根据模拟结果, 当基区少子扩散长度 较大 $(\geqslant 20 \mu \mathrm{m})$ 时, 活性层厚度仅 $2 \mu \mathrm{m}$ 的晶体硅薄膜 太阳电池可获得高达 $13 \%$ 的效率. 显然, 该模拟结果 对于没有任何背面陷光结构的外延晶体硅薄膜太阳
电池而言是极不合理的. 后来励旭东 ${ }^{[22]}$ 也利用 PC1D 讨论了外延晶体硅薄膜太阳电池的结构设计和影响 效率的主要因素, 但是所考虑的器件结构过于简化, 仅由祄底和晶体硅活性层(基区和发射区) 2 部分组成. 此外, 参数设置也存在过于理想化的问题, 譬如假定 串联电阻为零, 并联电阻为无穷大, 二极管暗饱和电 流为零等. 然而, 根据我们的实验研究结果 ${ }^{[21]}$, 过高 的二极管暗饱和电流和过低的并联电阻是限制所制 备的外延晶体硅薄膜太阳电池效率的主要因素.

针对以往研究工作的不足, 本文将采用更接近 实际情况的器件结构和参数对外延晶体硅薄膜太阳 电池进行 PC1D 模拟. 在此基础上, 对器件的各个组 成部分进行系统的优化. 此外, 我们还研究了基区少 子扩散长度、表面复合速度、并联电阻和二极管暗饱 和电流对电池效率的影响. 为了反映多个参数同时 变化对电池效率的影响, 我们给出了四参数 (电池效 率与其他 3 个参数)关系图.

\section{PC1D 模拟软件介绍}

\subsection{PC1D 模拟软件的优缺点}

PC1D 模拟软件具有如下优点 ${ }^{[9 ~ 13]}$. 1) 对计算机 软、硬件的要求都较低, 能够在个人电脑(只要 $\mathrm{CPU}$ 有内置算术协同处理器就行)上运行, 无需使用专用 的服务器. PC1D5.0 版本是 32-bit 程序, 运行环境要 求是 Windows95/Windows NT 或以上的操作系统. 现 在的个人电脑几乎都能满足运行 PC1D 的要求. 2) 采 用对用户友好的 Windows 操作界面, 简单、直观、易 于使用. 例如 Parameter 视图界面左边提供模拟参数 列表, 右边提供被模拟器件的结构图, 当改变参数设 置时两者实时提供视觉反馈. 3) 可输出多种物理量 的关系图, 譬如载流子浓度、电流密度、产生与复合 率、电势和场强等物理量与位置的关系曲线、光照 $I-V$ 特性及功率曲线、量子效率与反射率曲线等, 这对于 全面分析太阳电池的性能很有帮助. 4) 更强大的模 拟功能、更大的灵活性和更宽的适用性. 可以对最多 5 个区组成的太阳电池进行模拟，每个区可使用不同 的材料及参数设置; 支持两次扩散, 杂质分布可选择 均匀分布、指数分布、高斯分布、余误差函数分布或 者直接使用实测杂质分布数据的外部文件; 可以对 电池前、后表面织构、表面蒸镀单层或多层减反射膜 等陷光结构进行模拟, 可以设置光在电池内部前、后 
表面的反射特性(漫反射或镜面反射及两次反射率的 值), 可以使用实测的电池表面反射率的外部文件; 可以最多设置 4 个二极管或并联电阻这样的内部分 流元等. 5)更准确的性能预测结果和更快的收玫速度. 经过 20 多年不断丰富和完善所使用的物理模型、材 料特性参数和数值模拟计算方法等, 如今 PC1D 对太 阳电池性能的模拟既快又准, 特别是对晶体硅太阳 电池的模拟具有极高的准确性和可靠性.

PC1D 模拟软件的缺点主要表现在：1）PC1D 没 有包含反映氢化非晶硅材料的特性参数和物理模型, 因此不能对包含氢化非晶硅材料的太阳电池进行模 拟；2）PC1D 是一维模拟软件, 决定了它不能对具有 二维或三维结构不均匀性的太阳电池譬如 BPC (backside point contact) 电池和 EWT (emitter wrap through)电池进行精细地数值模拟. 当然, 可使用等 价结构或有效参数等方法把它们转化成一维器件, 然后利用 PC1D 对它们进行数值模拟研究.

\subsection{PC1D 模拟软件进行器件模拟的物理基础}

限于篇幅, 本文仅对 PC1D 器件模拟的物理基础 做一个简要的介绍. 有关这方面更详尽的描述可参 见文献[10]. PC1D 是通过求解太阳电池中电子和空 穴在准一维传输时所满足的如下半导体基本方程进 行器件模拟的.

$$
\begin{gathered}
J_{n}=-q n \mu_{n}(x)\left[\frac{\partial \psi}{\partial x}+\frac{\mathrm{d} \phi_{n}}{\mathrm{~d} x}\right]+q D_{n}(x) \frac{\partial n}{\partial x}, \\
\frac{\partial n}{\partial t}=\frac{1}{q} \frac{\partial J_{n}}{\partial x}+G(x, t)-R(n, p), \\
J_{p}=-q p \mu_{p}(x)\left[\frac{\partial \psi}{\partial x}-\frac{\mathrm{d} \phi_{p}}{\mathrm{~d} x}\right]-q D_{p}(x) \frac{\partial p}{\partial x}, \\
\frac{\partial p}{\partial t}=-\frac{1}{q} \frac{\partial J_{p}}{\partial x}+G(x, t)-R(n, p), \\
\frac{\partial^{2} \psi}{\partial x^{2}}=-\frac{q}{\varepsilon}\left[p-n+N_{D}(x)-N_{A}(x)\right],
\end{gathered}
$$

式中, $J_{n}, J_{p}$ 是电子和空穴电流密度; $q$ 是电子电 量; $n$ 和 $p$ 是电子和空穴浓度; $\mu_{n}$ 和 $\mu_{p}$ 是电子和空 穴迁移率; $\psi$ 是电势; $x$ 是位置坐标; $t$ 是时间; $\phi_{n}$ 和 $\phi_{p}$ 是考虑了因重掺杂造成的带隙变窄量, 对于 $\mathrm{N}$ 型材料只考虑导带, 对于 $\mathrm{P}$ 型材料只考虑价带; $D_{n}$ 和 $D_{p}$ 是电子和空穴扩散系数; $G$ 是产生率, $R$ 是复
合率； $N_{D}$ 是施主杂质浓度， $N_{A}$ 是受主杂质浓度. 其 中, $n, p, J_{n}, J_{p}$ 和 $\psi$ 都是位置和时间的函数. 方程 (1)和(3)是电子和空穴电流密度的表达式，它们表示 太阳电池内任意位置处的电流密度都是由漂移电流 和扩散电流 2 部分组成(也称为漂移-扩散近似). 方程 (2)和(4)来自于电荷守恒定律或连续性方程. 方程(5) 是求解静电场问题的泊松方程. 通过将方程(1)代入 (2), (3)代入(4)可消去 $J_{n}$ 和 $J_{p}$, 化简成含有 3 个未知 数 $n, p$ 和 $\psi$ 的 3 个基本方程.

PC1D 利用有限元方法求解上述 3 个基本方程, 从而实现对太阳电池的器件模拟. 具体做法如下: 首 先将厚度 $L$ 的一维太阳电池分割(或离散)为 $M$ 个单元. 然后在每个长度单元内求解这 3 个基本方程. 由于相 邻单元在分割点(或节点)位置上的 $n, p$ 和 $\psi$ 值相等, 这样就把每个长度单元上的 3 个基本方程联系(或耦 合)在一起. 每个长度单元内的光生载流子的产生率 根据材料的光吸收特性和 $\mathrm{AM} 1.5 \mathrm{G}$ 光谱计算, 复合率 则根据直接复合、Auger 复合和通过带隙态的 Schockley-Read-Hall 复合的有关公式计算三者的和. 除了上述方程以外, 每个边界处还存在 3 个分别以电 中性条件、偏置电压和表面复合为基础建立的方程, 因此，对于 $M$ 个单元，总共有包含 $3(M+1)$ 个变量的 $3(M+1)$ 个方程. PC1D 软件使用迭代法求解这 3 $(M+1)$ 个完全耦合非线性方程构成的方程组. 通过人为给 定初始条件, PC1D 软件首先对给定初始条件下的完 全耦合非线性方程组求解，然后以本次 $n, p$ 和 $\psi$ 的解 构造新的 $n, p$ 和 $\psi$ ，再代入到完全耦合非线性方程组; 通过重复这种数值迭代过程, 直到所有方程都收玫 (或达到自洽), 这样就得到了太阳电池性能的数值模 拟解.

\section{2 模拟电池的器件结构及参数设置}

外延晶体硅薄膜太阳电池主要由祄底、重掺杂背 表面场(back surface field, BSF)层、基区(P区)、发射 区 $(\mathrm{N}$ 区)、减反射层和前后表面电极组成, 具体的器 件结构图可参见文献[23]. 由于 BSF 层和 P 型硅活性 层是通过改变 $\mathrm{B}_{2} \mathrm{H}_{6}$ 流量在一个外延生长过程沉积完 成的, 因此 BSF 层与 $\mathrm{P}$ 型硅活性层之间往往夹有一个 “过渡区”。扩展电阻测量结果表明 ${ }^{[20]}$ ，“过渡区”的厚 度在 $4 \mu \mathrm{m}$ 左右, 掺杂浓度逐步由 BSF 层的重掺杂过 
渡到基区的中等掺杂. 为了使 PC1D 模拟的器件结构 更符合真实的情况, 我们将外延晶体硅薄膜太阳电 池分成 4 个区, 即祄底、BSF 层、过渡区和基区(通过 在基区前表面扩磷形成发射区), 如图 1 所示. 表 1 列 出了模拟所使用的参数. 这些参数值或取自于文献 $[20,22]$ 或来自于我们的实验研究结果 ${ }^{[23]}$. 需要说明 的是, 为了简化, 假定过渡区具有固定的少子扩散长 度, 其数值取 $20 \mu \mathrm{m}$. 为了使模拟结果更接近实测值, 激活了 2 个“内部分流源”. 一个为二极管, 其暗饱和 电流 $I_{0}=1 \times 10^{-8} \mathrm{~A}$, 另一个为并联电阻, 其阻值为 $300 \Omega$. 由于电池正表面缺乏有效的针化, 我们假定 正表面的复合速度为 $1 \times 10^{5} \mathrm{~cm} / \mathrm{s}$. 考虑到在外延生长 的界面会存在较多的晶体缺陷, BSF 层与祄底交界面 的复合速度取 $1 \times 10^{5} \mathrm{~cm} / \mathrm{s}$. 由于 $\mathrm{BSF}$ 层与过渡层通过 一次外延生长完成, 两者界面处的晶体缺陷应很少, 复合速度取 $5000 \mathrm{~cm} / \mathrm{s}$. 如图 1 所示. 最后需要说明的 是, 模拟电池的面积为 $1 \mathrm{~cm}^{2}$; 模拟测试条件为: $25^{\circ} \mathrm{C}$, $\mathrm{AM} 1.5 \mathrm{G}$ 光谱, 光强为 $1000 \mathrm{~W} / \mathrm{m}^{2}$.

根据表 1 中的参数设置, 图 2 给出了 PC1D 模拟 的外延晶体硅薄膜太阳电池的 $I-V$ 特性和光谱响应曲 线. 结果表明: 短路电流 $I_{\mathrm{sc}}=0.0297 \mathrm{~A}$, 开路电压 $V_{\mathrm{oc}}=0.3818 \mathrm{~V}$, 填充因子 $F F=0.73$, 效率 $\eta=8.3 \%$. 由 光谱响应曲线可知, 三层减反射膜具有非常优秀的 陷光效果, 在 400 到 $1200 \mathrm{~nm}$ 的波长范围表面反射率 低于 $10 \%$. 由于光吸收层仅有 $35 \mu \mathrm{m}$ 厚, 电池对长波 光子的吸收明显不足, 当光的波长大于 $800 \mathrm{~nm}$ 以后,
电池的量子效率下降得很快. 作为比较, 电池在 400 到 $800 \mathrm{~nm}$ 的波段具有非常好的光谱响应( $90 \%)$.

\section{3 结果与讨论}

表 1 所列参数定义的外延晶体硅薄膜太阳电池 是我们模拟工作的起点, 在此基础上, 我们将利用 PC1D 模拟不同参数设置对电池效率的影响, 从而对 电池参数做进一步优化.

\subsection{BSF 层厚度和掺杂浓度对电池效率的影响 (BSF 层参数优化)}

BSF 层参数的优化主要涉及厚度和掺杂浓度这 2

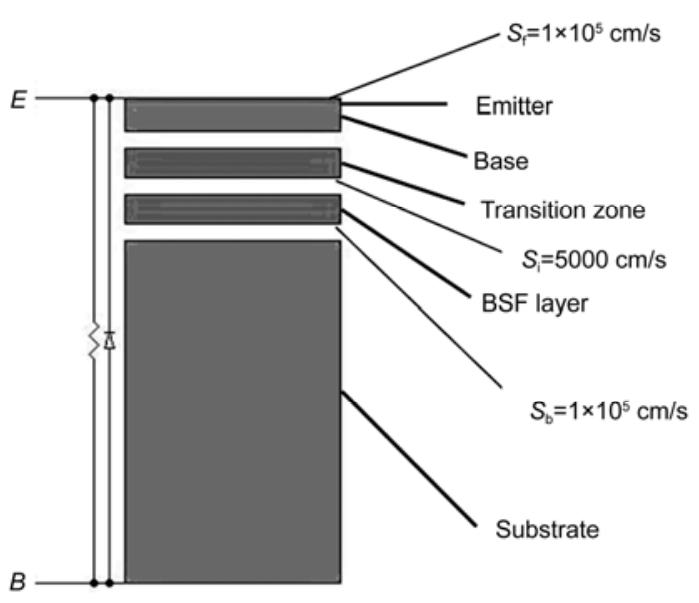

图 1 模拟所使用的外延晶体硅薄膜太阳电池的器件结构

\section{表 1 PC1D 模拟外延晶体硅薄膜太阳电池所使用的参数}

\begin{tabular}{|c|c|}
\hline Device component & Parameter setting description \\
\hline Substrate & $\begin{array}{l}\text { Non-active } \mathrm{P} \text { type crystalline silicon substrate, } 300 \mu \mathrm{m} \text { thick, } 1.375 \times 10^{20} \mathrm{~cm}^{-3} \text { doping, } \rho=0.001 \Omega \mathrm{cm} \text {, the minority } \\
\text { carrier diffusion length took the maximum value which was only limited by Auger recombination corresponding to the } \\
\text { doping level. }\end{array}$ \\
\hline BSF layer & $\begin{array}{l}6 \mu \mathrm{m} \text { thick, } 9 \times 10^{18} \mathrm{~cm}^{-3} \text { doping, the recombination rate of interface between the BSF layer and substrate took } 1 \times 10^{5} \\
\mathrm{~cm} / \mathrm{s} \text {, the diffusion length took the maximum value corresponding to the Auger recombination limit. }\end{array}$ \\
\hline Transition zone & $\begin{array}{l}4 \mu \mathrm{m} \text { thick, erfc function doping profile, gradually changing from the BSF layer's heavy doping to the base's } \\
\text { moderate doping, the recombination rate of interface between the transition zone and BSF layer took } 5000 \mathrm{~cm} / \mathrm{s} \text {, the } \\
\text { diffusion length was assigned } 20 \mu \mathrm{m} \text {. }\end{array}$ \\
\hline Base & $35 \mu \mathrm{m}$ thick, $1 \times 10^{17} \mathrm{~cm}^{-3}$ doping, $\rho=0.1932 \Omega \mathrm{cm}$, the diffusion length took $60 \mu \mathrm{m}$. \\
\hline Emitter & $\begin{array}{l}\text { Erfc function profile for phosphorus doping, the emitter sheet resistance and junction depth took } 60 \Omega / \square \text { and } 0.4 \\
\mu \mathrm{m} \text {, respectively. The front surface recombination rate was assigned } 1 \times 10^{5} \mathrm{~cm} / \mathrm{s} \text {. }\end{array}$ \\
\hline Circuit part & $\begin{array}{l}\text { The series resistance, parallel resistance and diode dark saturation current were } 0.1 \Omega, 300 \Omega \text { and } 1 \times 10^{-8} \mathrm{~A} \text {, } \\
\text { respectively. }\end{array}$ \\
\hline $\begin{array}{l}\text { Light trapping } \\
\text { condition }\end{array}$ & 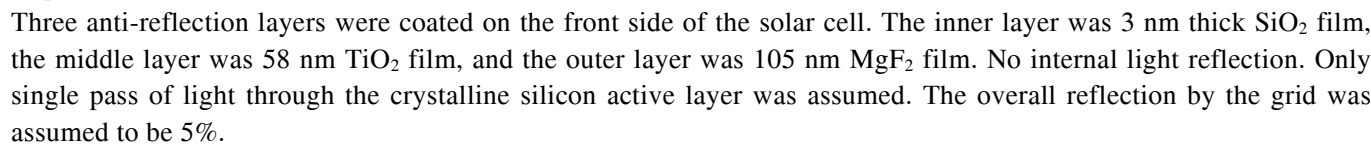 \\
\hline
\end{tabular}



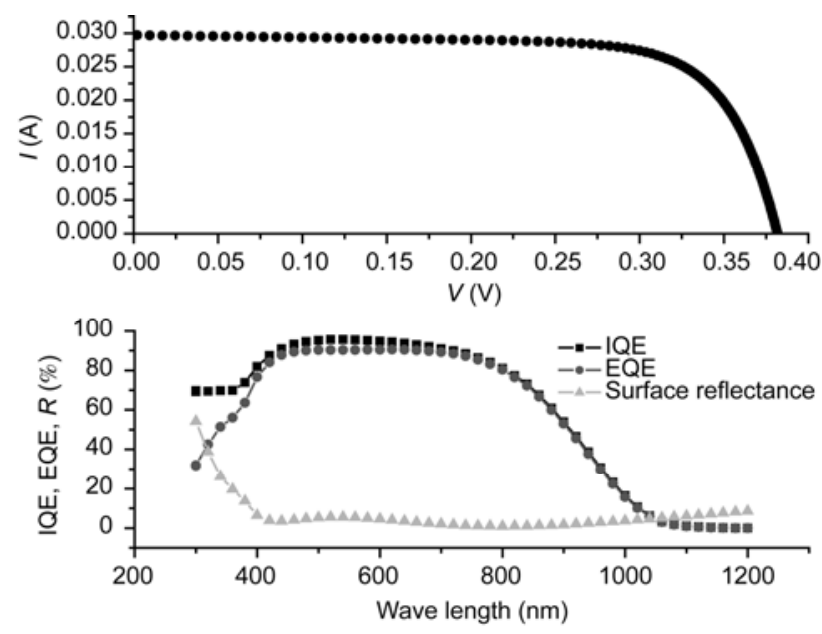

图 2 表 1 定义的外延晶体硅薄膜太阳电池的 $I-V$ 特性及光 谱响应模拟曲线

个参数. 由于插入 BSF 层的目的是为了减小光生少 数载流子在活性层与衬底界面上的复合, 为此, 我们 以 BSF 层与祄底交界面的复合速度 $S_{\mathrm{b}}$ 为参数, 利用 PC1D 模拟了 BSF层厚度和掺杂浓度对电池效率的影 响. 模拟中, 除了模拟参数以外, 其他参数设置与表 1 相同. 图 3 给出了模拟结果. 由图 3 可知, 与 BSF 层厚度相比, BSF 层掺杂浓度对电池效率的影响更显 著. 在所研究的 BSF 层厚度范围 $(2 \sim 12 \mu \mathrm{m})$, 电池效 率随 BSF 层掺杂浓度的增加而增加. 作为比较, 电池 效率随 $\mathrm{BSF}$ 层厚度的增加只是在 BSF 层掺杂浓度较 小 $\left(\sim 1 \times 10^{17} \mathrm{~cm}^{-3}\right)$ 时才比较明显, 当 BSF 层掺杂浓度 较大 $\left(>1 \times 10^{18} \mathrm{~cm}^{-3}\right)$ 时, BSF 层厚度对电池效率的影响 可忽略不计. 有趣的是, 我们注意到 BSF 层的最佳掺 杂浓度 (对应于 $8.33 \%$ 以上的电池效率)下限随着界面 复合速度 $S_{\mathrm{b}}$ 的增大而减小, 从 $S_{\mathrm{b}}=1 \times 10^{4} \mathrm{~cm} / \mathrm{s}$ 时的 $2 \times 10^{19} \mathrm{~cm}^{-3}$ 减小到 $S_{\mathrm{b}}=1 \times 10^{5} \mathrm{~cm} / \mathrm{s}$ 时的 $1 \times 10^{19} \mathrm{~cm}^{-3}$, 再减小到 $S_{\mathrm{b}}=1 \times 10^{6} \mathrm{~cm} / \mathrm{s}$ 时的 $5 \times 10^{18} \mathrm{~cm}^{-3}$. 此外, 当 $S_{\mathrm{b}}=1 \times 10^{4} \mathrm{~cm} / \mathrm{s}$ 或 $1 \times 10^{5} \mathrm{~cm} / \mathrm{s}$ 时, BSF 层的最佳掺杂浓 度几乎不受 $\mathrm{BSF}$ 层厚度的影响, 然而, 当 $S_{\mathrm{b}}=1 \times 10^{6}$ $\mathrm{cm} / \mathrm{s}$ 时, BSF 层的最佳掺杂浓度在 BSF 层厚度 4 7 $\mu \mathrm{m}$ 之间取最小值 $\left(1.8 \times 10^{18} \mathrm{~cm}^{-3}\right)$. 在获得理想电池效 率的前提下, 我们总是希望 BSF 层厚度和掺杂浓度 越小越好. BSF 层厚度越小意味着材料耗费越少, 成 本越低, 而掺杂浓度越小意味着 BSF 层的晶体质量 越好, 对掺杂气体的消耗也越少. 经过权衡考虑, 当 界面复合速度 $S_{\mathrm{b}}$ 的取值区间在 $1 \times 10^{4} \mathrm{~cm} / \mathrm{s}$ 至 $1 \times 10^{6}$
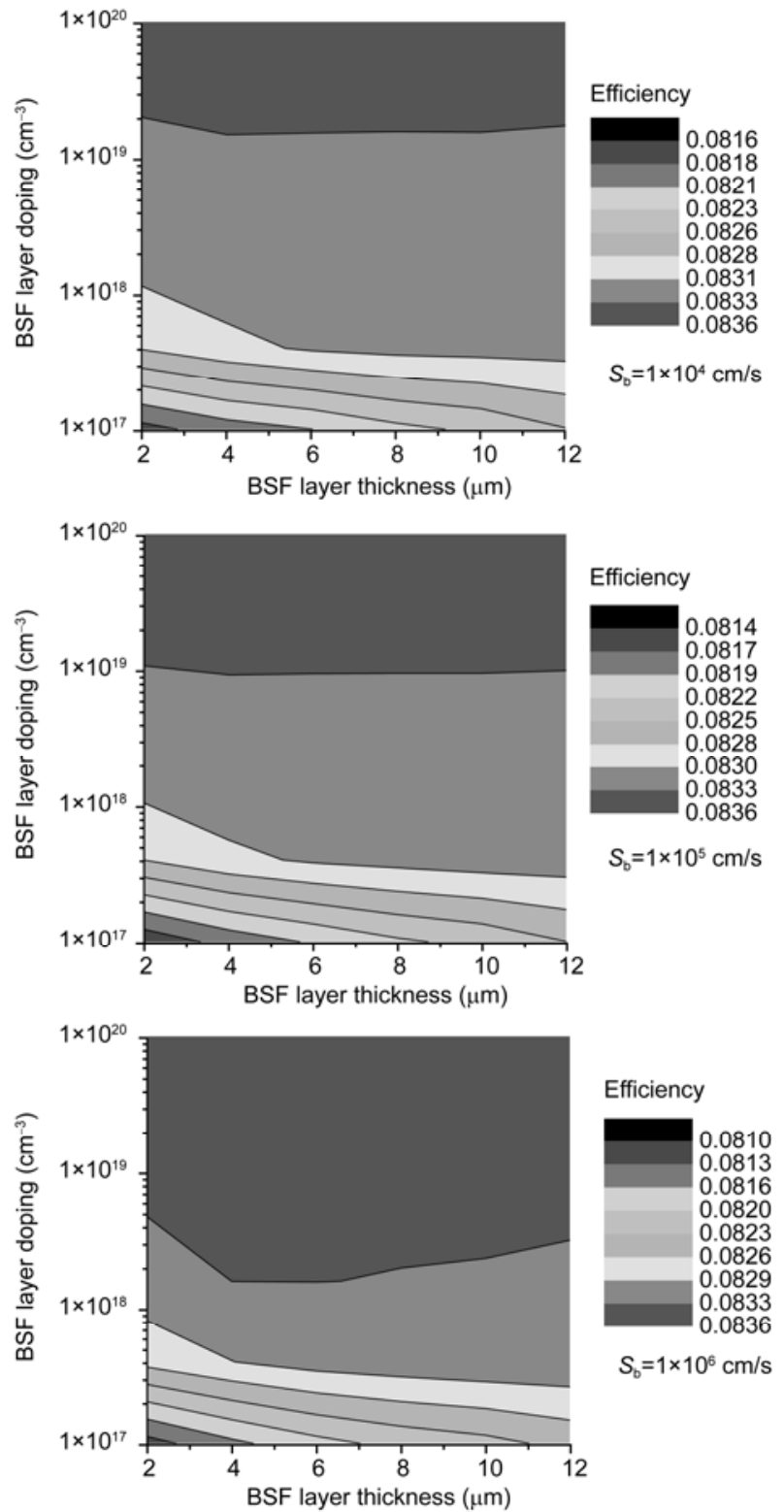

图 3 电池效率与 BSF 层厚度和掺杂浓度的关系 (以 BSF 层 与祄底交界面的复合速度 $S_{\mathrm{b}}$ 为参数)

$\mathrm{cm} / \mathrm{s}$ 时, BSF 层厚度取 $4 \mu \mathrm{m}$ 、掺杂浓度取 $2 \times 10^{19} \mathrm{~cm}^{-3}$ 时, 电池可获得理想的性能表现. 在以下模拟中, 我 们将使用优化后的 BSF 层参数.

上述模拟结果可以从背表面场(BSF)的工作原理 得到解释. 所谓背表面场就是在 $\mathrm{P}$ 型硅活性层与祄底 之间引入一个重掺杂的 $\mathrm{P}^{+}$层, 与 $\mathrm{P}$ 型硅活性层形成所 谓的“高低结”. 仔细的物理分析可知, 在 $\mathrm{P}^{+}$层与 $\mathrm{P}$ 层 界面形成的内建电场由 $\mathrm{P}$ 区指向 $\mathrm{P}^{+}$区, 该电场可有效 
阻止 P 区内的少数载流子(电子)向电池背表面扩散, 因此可有效减小少子在电池背表面处的复合. 另一 方面, 通过引入背表面场, 电池背面的欧姆接触变得 更加容易, 因此, 背表面场的引入可有效提高电池的 效率. 由 $\mathrm{BSF}$ 的工作原理不难看出, $\mathrm{P}^{+}$层与 $\mathrm{P}$ 层界面 形成的内建电场随着 BSF 层 (即 $\mathrm{P}^{+}$层) 掺杂浓度的增 加而增加, 这意味着少子在电池背表面处的复合会 随着 BSF 层(即 $\mathrm{P}^{+}$层) 掺杂浓度的增加而降低. BSF 层 厚度对电池效率的影响只有当 BSF 层掺杂浓度较低 时才会有所体现, 这是因为当 BSF 层掺杂浓度较高 时 “高低结”空间电荷区向 $\mathrm{P}^{+}$层的扩展有限, 而当掺 杂浓度较低时向 $\mathrm{P}^{+}$层的扩展较深所致. 至于 $\mathrm{BSF}$ 层 的最佳掺杂浓度下限为什么会随着界面复合速度 $S_{\mathrm{b}}$ 的增大而减小的具体原因尚不清楚, 我们认为这至 少与 $\mathrm{BSF}$ 层的少子扩散长度随着 $\mathrm{BSF}$ 层掺杂浓度的 减小而增加有关.

\section{2 基区厚度和掺杂浓度对电池效率的影响(基区 参数优化)}

在基区电学质量(主要用基区少子扩散长度 $L_{\mathrm{D}}$ 来 表征)一定的前提下, 基区参数的优化主要涉及厚度 和掺杂浓度这 2 个参数, 因此, 我们以 $L_{\mathrm{D}}$ 为参数, 利 用 PC1D 模拟了基区厚度和掺杂浓度对电池效率的 影响. 模拟中, 除了模拟参数和已优化的 BSF 层参数 以外, 其他参数设置与表 1 相同. 需要说明的是, 对 于不同的基区掺杂浓度，通过设定发射区峰值掺杂 浓度、发射区掺杂浓度余误差函数(erfc)分布的深度 因子使发射区的方块电阻和结深保持不变. 图 4 给出 了模拟结果. 由图 4 可知, 电池效率受 $L_{\mathrm{D}}$ 的影响极大. 当 $L_{\mathrm{D}}$ 从 $5 \mu \mathrm{m}$ 增加到 $60 \mu \mathrm{m}$ 时, 电池的最高效率从 6\%提高到 9\%, 增幅达到 50\%. 当晶体硅活性层的晶 体质量很差、 $L_{\mathrm{D}}$ 只有 $5 \mu \mathrm{m}$ 时, 在所研究的基区厚度 范围 $(5 \sim 40 \mu \mathrm{m})$, 基区厚度越接近 $L_{\mathrm{D}}$, 电池的效率越 高. 换句话说, 为了获得理想的电池效率, 基区厚度 应小于或等于 $L_{\mathrm{D}}$. 当晶体硅活性层的晶体质量较好、 $L_{\mathrm{D}}$ 较大 $(20 \mu \mathrm{m}$ 以上 $)$ 时, 要想获得理想的电池效率, $L_{\mathrm{D}}$ 应该至少是基区厚度的 2 倍. 如图 4 所示. 以上结 果说明, 基区不是越厚越好, 基区厚度的选择必须要 考虑 $L_{\mathrm{D}}$ 的值, 而后者主要决定于基区(或晶体硅活性 层)的晶体质量. 该结果与 Faller 给出的结论 ${ }^{[20]}$ 是一 致的. 此外, 我们注意到在所研究的基区掺杂浓度范 围 $\left(5 \times 10^{15} \sim 5 \times 10^{18} \mathrm{~cm}^{-3}\right)$ 更高的电池效率总是在更小
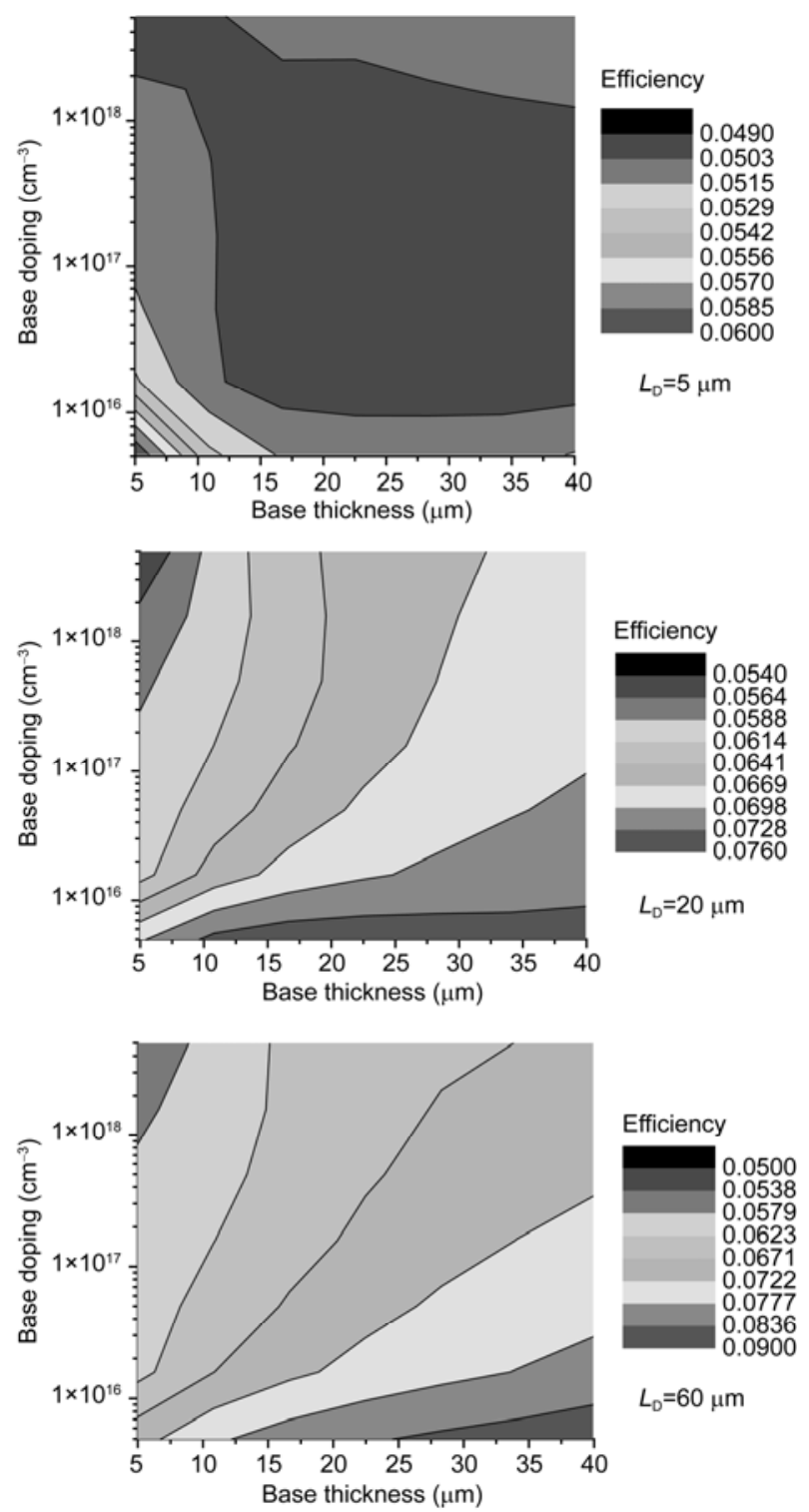

图 4 电池效率与基区厚度和掺杂浓度的关系(以基区少子 扩散长度 $\boldsymbol{L}_{\mathrm{D}}$ 为参数)

的基区掺杂浓度和更大的基区厚度的条件下获得. 相比较而言, 基区掺杂浓度对电池效率的影响比基 区厚度对电池效率的影响显著. 根据以上模拟结果, 基区掺杂浓度应该取 $N_{\mathrm{A}}=5 \times 10^{15} \mathrm{~cm}^{-3}$ (对应于 $\rho=2.838$ $\Omega \mathrm{cm}$ ), 但是, 考虑到晶体硅薄膜中的晶界势垒在低 掺杂时较高, 人们通常采用较高的掺杂浓度来降低 晶界势垒高度, 减小晶界对晶体硅活性层电学性质 的影响 ${ }^{[24]}$. 为此, 我们选取的最佳基区掺杂浓度为 $5 \times 10^{16} \mathrm{~cm}^{-3}$ (对应于 $\rho=0.3441 \Omega \mathrm{cm}$ ), 并应用于下面 的模拟中. 事实上, 基区掺杂浓度是唯一需要优化的 
参数, 因为通过平衡光吸收和材料成本, 外延晶体硅 薄膜太阳电池活性层的厚度已被优化为 $35 \mu \mathrm{m}{ }^{[20]}$. 需要说明的是, $35 \mu \mathrm{m}$ 厚的晶体硅活性层虽不能完全 吸收可见光区的太阳光谱, 但已能够吸收约 $80 \%$ 的 太阳光, 而且已有实验证明活性层厚度为 $35 \mu \mathrm{m}$ 的晶 体硅薄膜太阳电池可获得接近 $18 \%$ 的效率 ${ }^{[20]}$.

上述模拟结果可以从 $\mathrm{pn}$ 结太阳电池的工作原理 得到解释. $\mathrm{pn}$ 结太阳电池本质上是扩散过程起主导作 用的少子器件. 具体地说, 只有光吸收层(主要是基 区)中的光生少数载流子扩散到 pn 结附近、并且被内 建电场分离, 才能对光生电流作出贡献, 因此, 基区 少子扩散长度 $L_{\mathrm{D}}$ 对电池效率的影响极大. 基区不是 越厚越好, 基区厚度的选择必须要考虑 $L_{\mathrm{D}}$ 的值, 这 是由太阳电池的效率同时取决于光吸收过程和光生 少数载流子的扩散过程决定的. 当 $L_{\mathrm{D}}$ 较小时, 基区 的最佳厚度应小于或等于 $L_{\mathrm{D}}$; 当 $L_{\mathrm{D}}$ 较大时, $L_{\mathrm{D}}$ 应该 至少是最佳基区厚度的 2 倍. 这个结论从图 5 很容易 得出. 如图 5 所示, 由于光生载流子会在基区各处产 生并以随机方向扩散，若在基区的末端产生，则 $L_{\mathrm{D}}$ 应大于或等于基区厚度, 才能保证朝 pn 结方向运动 的光生少子(如电子 1 和 2) 能够到达 $\mathrm{pn}$ 结处从而被内 建电场分离. 当 $L_{\mathrm{D}}$ 是基区厚度的 2 倍时, 即使产生于 $\mathrm{pn}$ 结附近、朝电池背面运动的光生少子 (如电子 3 ) 被 BSF 层反射回来也能够被 pn 结收集. 显然, 此时基 区中的绝大多数光生少子都能够被 pn 结收集. 即使 如此, 仍有一小部分光生少子(如电子 4)无法被收集. 若要使电池效率不受 $L_{\mathrm{D}}$ 的限制, $L_{\mathrm{D}}$ 应该至少是基区 厚度的 3 倍以上, 这意味着对于所讨论的晶体硅薄膜

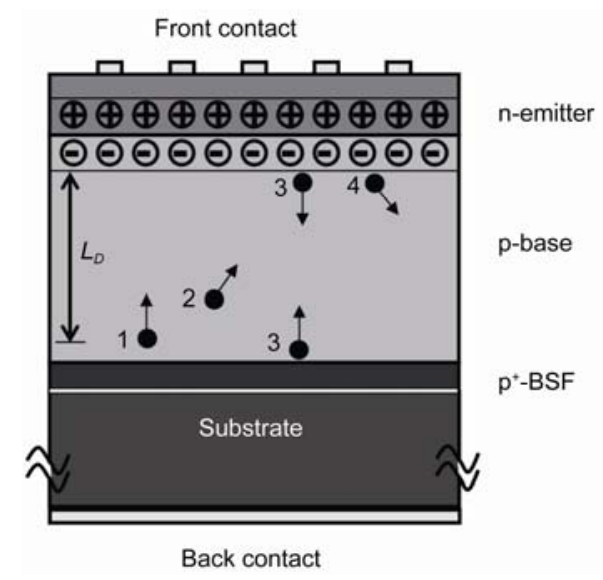

图 5 基区少子扩散长度 $L_{\mathrm{D}}$ 对晶体硅薄膜电池效率影响的 示意图
太阳电池，相应的 $L_{\mathrm{D}}$ 应该在 $105 \mu \mathrm{m}$ 以上. 显然, 在 所研究的参数变化范围(晶体硅活性层厚度 $35 \mu \mathrm{m}, L_{\mathrm{D}}$ 取值 5 60 $\mu \mathrm{m}$ ), 电池效率主要受不足的基区少子扩 散长度 $L_{\mathrm{D}}$ 的限制. 换句话说, 与光吸收过程相比, 光 生少数载流子的扩散过程对电池效率的影响起决定 作用. 由于更小的基区掺杂浓度意味着更好的晶体 质量和更大的 $L_{\mathrm{D}}$, 所以更高的电池效率总是在更小 的基区掺杂浓度下获得，而且基区掺杂浓度对电池 效率的影响比基区厚度对电池效率的影响显著.

\section{3 发射区方块电阻和结深对电池效率的影响(发 射区参数优化)}

在发射区表面钝化情况(主要用正表面复合速度 $S_{\mathrm{f}}$ 来表征)一定的前提下, 发射区参数的优化主要涉 及方块电阻和结深这 2 个参数, 为此, 我们以 $S_{\mathrm{f}}$ 为参 数, 利用 PC1D 模拟了发射区方块电阻和结深对电池 效率的影响. 模拟中, 除了已优化的参数和模拟参数 以外，其他参数设置与表 1 相同. 图 6 给出了模拟结 果. 由图 6 可知, 电池效率随着 $S_{\mathrm{f}}$ 的增加而减小, 随 着结深的减小而增加. 该结果与励旭东给出的结论 ${ }^{[17]}$ 是一致的. 此外, 结深对电池效率的影响比方块电阻 对电池效率的影响显著. 当 $S_{\mathrm{f}}$ 较小 $\left(S_{\mathrm{f}}=1 \times 10^{4} \mathrm{~cm} / \mathrm{s}\right)$ 时, 在所研究的参数范围(发射区方块电阻从 40 变到 90 $\Omega / \square$, 结深从 0.2 变到 $1.2 \mu \mathrm{m}$ )内, 发射区更浅的结深 和更大的方块电阻可获得更高的电池效率. 随着 $S_{\mathrm{f}}$ 的增大，发射区方块电阻对电池效率的影响逐渐减 弱. 当 $S_{\mathrm{f}}$ 增大到 $1 \times 10^{6} \mathrm{~cm} / \mathrm{s}$ 时，电池效率几乎不受发 射区方块电阻的影响. 如图 6 所示. 需要说明的是, 为了简化，我们并没有考虑发射区方块电阻对电池 串联电阻的影响. 在获得理想电池效率的前提下, 我 们总是希望发射区方块电阻越小越好，因为发射区 方块电阻越小意味着电池的串联电阻越小. 综合考 虑图 6 给出的 3 种情况和扩散工艺的可行性, 我们优 化出的发射区参数如下：结深取 $0.23 \mu \mathrm{m}$, 发射区方 块电阻取 $75 \Omega / \square$. 它们将被应用在下面的模拟中.

上述模拟结果可以从“浅结、高方阻发射区”提高 pn 结太阳电池效率的原理得到解释. 与晶体硅太阳 电池类似, 晶体硅薄膜太阳电池的 $\mathrm{n}$ 型发射区也是通 过将 $\mathrm{p}$ 型硅活性层表面扩磷形成的，因此 $\mathrm{n}$ 型发射区 的掺杂浓度要远高于 $\mathrm{p}$ 型基区，这就使得 $\mathrm{n}$ 型发射区 的少子扩散长度远低于 $\mathrm{p}$ 型基区. 另一方面，晶体硅 对波长 $400 \mathrm{~nm}$ 以下的高能光子的吸收很强(光吸收系 

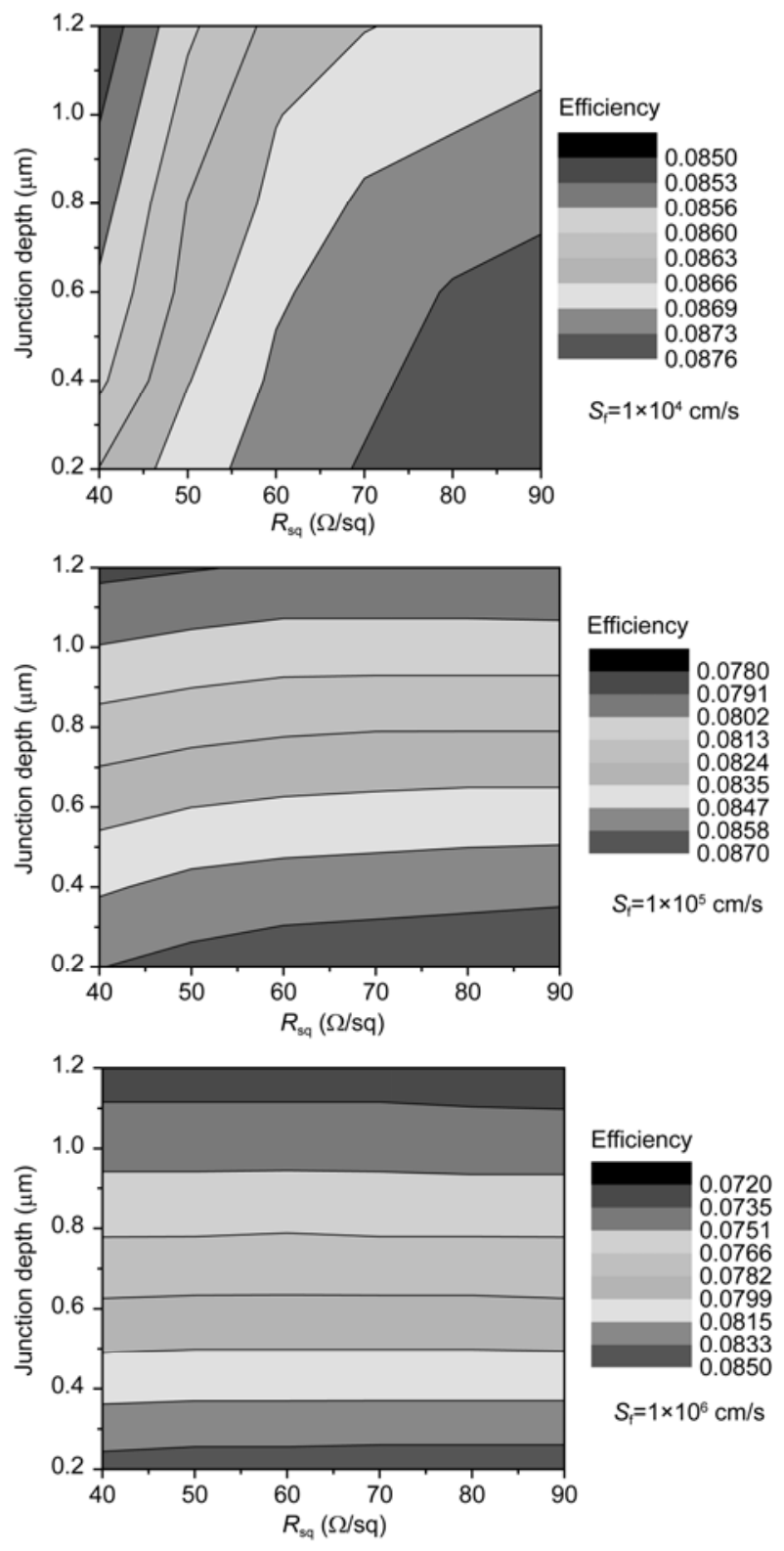

图 6 电池效率与发射区方块电阻 $\boldsymbol{R}_{\mathrm{sq}}$ 和结深的关系(以正表 面复合速度 $S_{\mathrm{f}}$ 为参数)

数在 $10^{5} \mathrm{~cm}^{-1}$ 至 $10^{6} \mathrm{~cm}^{-1}$ 量级). 以波长 $400 \mathrm{~nm}$ 的紫 光为例, 晶体硅对它的光吸收系数为 $9.52 \times 10^{4}$ $\mathrm{cm}^{-1[25]}$, 由此可计算出它在晶体硅中的穿透深度(定 义为光强衰减为入射光强的 $1 / \mathrm{e}$ 所对应的深度)仅为 $0.105 \mu \mathrm{m}$. 这意味着波长小于 $400 \mathrm{~nm}$ 的高能光子在 电池表面很薄的一层就被吸收殆尽. 为了避免高能 光子产生的少数载流子被电池表面的大量表面态和 发射区内的晶体缺陷复合掉, 就需要把 pn 结做到靠
近电池表面. 由于浅结器件可大幅提高太阳电池在 短波区域的光谱响应，所以它可大大提高电池的效 率. 发射区方块电阻对电池效率的影响主要是通过 改变发射区少子扩散长度来实现的. 发射区方块电 阻越大意味着磷掺杂浓度越小, 发射区少子扩散长 度越大, 进而电池效率越高. 从结深和方块电阻影响 电池效率的物理机制不难看出, 结深对电池效率的 影响远比方块电阻对电池效率的影响显著. “发射区 方块电阻仅仅在正表面复合速度较小时才会影响电 池效率” 是因为通常情况下电池正表面的表面态数目 远大于发射区内晶体缺陷的数目, 所以正表面复合 对电池效率的影响远比发射区体内复合对电池效率 的影响显著. 当正表面复合速度较大时, 由方块电阻 引起的发射区体内复合变化完全被更大的正表面复 合所掩盖, 所以此时发射区方块电阻对电池效率的 影响就体现不出来了.

\section{4 基区少子扩散长度和正表面复合速度对电池 效率的影响}

为了研究晶体硅活性层电学质量(主要用基区少 子扩散长度 $L_{\mathrm{D}}$ 来表征)和电池正表面钝化情况(主要 用正表面复合速度 $S_{\mathrm{f}}$ 来表征)对电池光电性能的影响, 我们以 BSF 层与祄底交界面的复合速度 $S_{\mathrm{b}}$ 为参数, 利用 PC1D 模拟了 $L_{\mathrm{D}}$ 和 $S_{\mathrm{f}}$ 对电池效率的影响. 模拟 中, 除了已优化的参数和模拟参数以外, 其他参数设 置与表 1 相同. 图 7 给出了模拟结果. 由图 7 可知, $L_{\mathrm{D}}$ 对电池效率的影响远比 $S_{\mathrm{f}}$ 对电池效率的影响显著. 电池效率随着 $L_{\mathrm{D}}$ 的增加单调递增, 然而 $S_{\mathrm{f}}$ 对电池效 率的影响较弱. 特别地, 当 $L_{\mathrm{D}}$ 较理想 $(\geqslant 65 \mu \mathrm{m})$ 时, 在 所研究的 $S_{\mathrm{f}}$ 范围 $\left(5 \times 10^{3} \sim 5 \times 10^{6} \mathrm{~cm} / \mathrm{s}\right)$, 电池都可取得 理想的效率( $\sim 9 \%)$, 且与 $S_{\mathrm{f}}$ 无关. 如图 7 所示. 通过比 较图 7 给出的 3 种情况, 我们注意到, 在所研究的参 数变化范围 $\left(S_{\mathrm{b}}=1 \times 10^{4} \sim 1 \times 10^{6} \mathrm{~cm} / \mathrm{s}\right)$, 电池效率几乎不 受 BSF 层与祄底交界面复合速度 $S_{\mathrm{b}}$ 的影响.

与直拉法或铸造法制备的体晶体硅相比, 用通 常的物理或化学方法沉积的晶体硅薄膜的晶体质量 要差很多, 这就造成晶体硅薄膜太阳电池的效率普 遍受到不足的基区少子扩散长度 $L_{\mathrm{D}}$ 的限制. 由前面 的讨论可知, 外延晶体硅薄膜太阳电池的晶体硅活 性层厚度为 $35 \mu \mathrm{m}$, 若要使电池效率不受 $L_{\mathrm{D}}$ 的限制, $L_{\mathrm{D}}$ 应该在 $105 \mu \mathrm{m}$ 以上, 而本文讨论的 $L_{\mathrm{D}}$ 在 5 到 80 $\mu \mathrm{m}$ 之间, 这意味着所讨论的外延晶体硅薄膜太阳电 

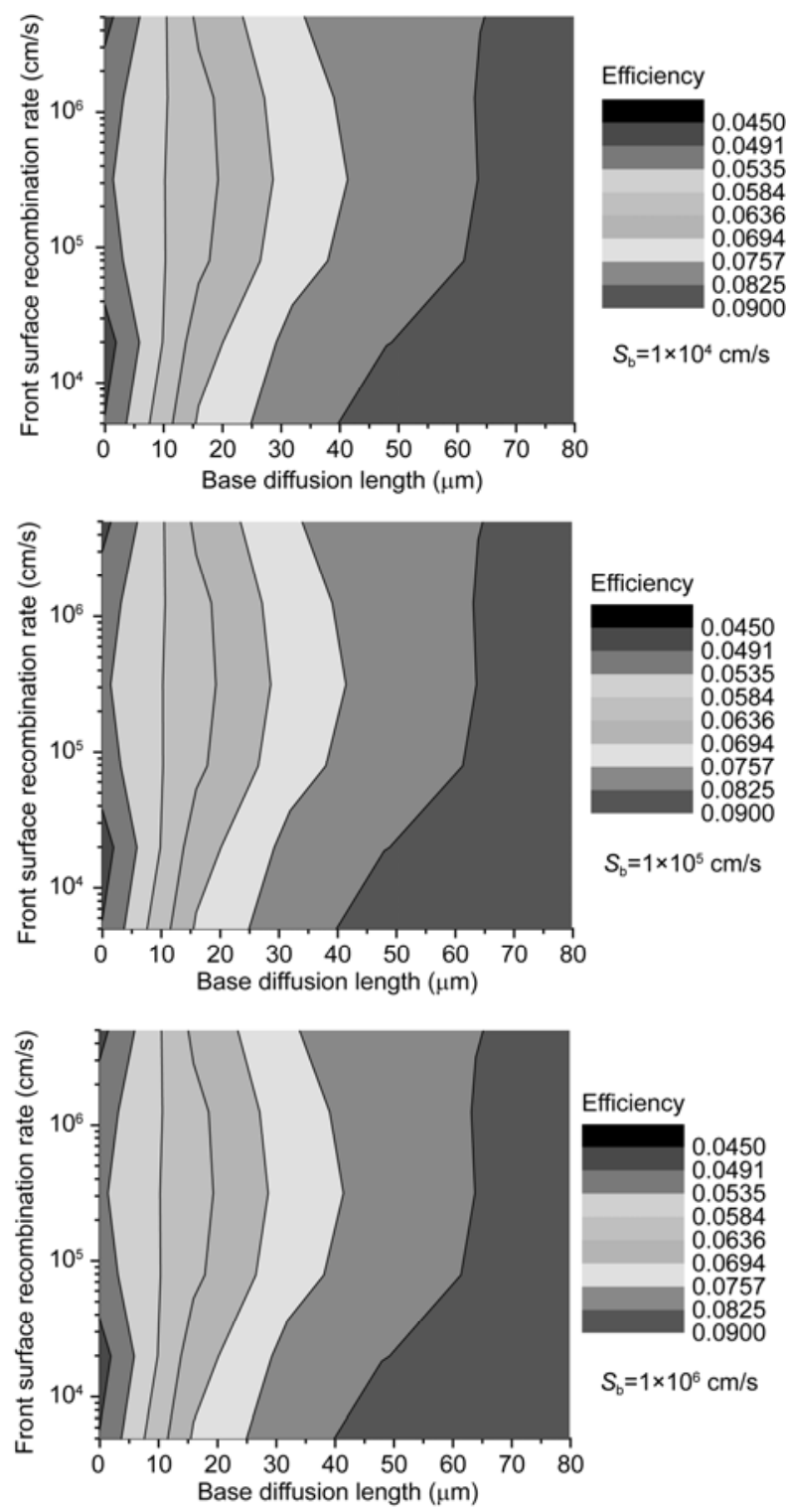

图 7 电池效率与基区少子扩散长度 $\boldsymbol{L}_{\mathrm{D}}$ 和正表面复合速度 $S_{\mathrm{f}}$ 的关系(以 BSF 层与祄底交界面的复合速度 $S_{\mathrm{b}}$ 为参数)

池的性能主要受到不足的 $L_{\mathrm{D}}$ 的限制, 或者 $L_{\mathrm{D}}$ 对外延 晶体硅薄膜太阳电池的效率起决定性影响. 基于以 上认识, 模拟给出的结论“基区少子扩散长度 $L_{\mathrm{D}}$ 对电 池效率的影响远比正表面复合速度 $S_{\mathrm{f}}$ 对电池效率的 影响显著”就不难理解了. 之所以得出“当 $L_{\mathrm{D}}$ 较为理 想时, 电池都可取得理想的效率, 且与 $S_{\mathrm{f}}$ 无关”的结 论, 是因为在所讨论的参数变化范围, 由 $L_{\mathrm{D}}$ 增大带 来的效率增益掩盖了由 $S_{\mathrm{f}}$ 增大造成的效率损失. 类 似地, “电池效率几乎不受 BSF 层与祄底交界面复合 速度 $S_{\mathrm{b}}$ 的影响”的结论也可得到相应的解释.

\section{5 串、并联电阻和二极管暗饱和电流对电池效率 的影响}

对于晶体硅薄膜太阳电池而言, 由晶界或杂质 引起的光生少数载流子的复合问题比较严重. 为了 研究晶体硅薄膜太阳电池体区复合(主要用二极管暗 饱和电流 $I_{0}$ 来表征)和 $\mathrm{pn}$ 结漏电(主要用并联电阻 $R_{\mathrm{sh}}$ 来表征)对电池光电性能的影响, 我们以串联电阻 $R_{\mathrm{s}}$ 为参数, 利用 $\mathrm{PC} 1 \mathrm{D}$ 模拟了 $I_{0}$ 和 $R_{\mathrm{sh}}$ 对电池效率的影 响. 模拟中, 除了已优化的参数和模拟参数以外, 其 他参数设置与表 1 相同. 图 8 给出了模拟结果. 由图 8 可知, 电池效率随着 $R_{\mathrm{sh}}$ 的增加而增加, 随着 $I_{0}$ 和 $R_{\mathrm{S}}$ 的减小而增加. 相对而言, $I_{0}$ 对电池效率的影响比 $R_{\mathrm{sh}}$ 和 $R_{\mathrm{s}}$ 对电池效率的影响显著. 当 $I_{0}$ 从 $5 \times 10^{-5} \mathrm{~A}$ 减 小到 $1 \times 10^{-8} \mathrm{~A}$ 时, 在所研究的参数范围 $\left(R_{\mathrm{sh}}\right.$ 从 $3 \Omega$ 变 到 $3000 \Omega, R_{\mathrm{S}}$ 从 $0.1 \Omega$ 变到 $\left.1 \Omega\right)$, 平均而言电池效率 从 3\%提高到 6\%. 此外, 由图 8 可知, 较小的 $I_{0}(\sim 1$ $\left.\times 10^{-8} \mathrm{~A}\right)$ 是获得理想电池效率 $(8 \%)$ 的前提条件. 较 大的 $R_{\mathrm{sh}}(1000 \Omega$ 以上 $)$ 和较小的 $R_{\mathrm{s}}(0.5 \Omega$ 以下 $)$ 有助于 获得理想的电池效率. 根据模拟结果, 我们选取 $R_{\mathrm{sh}}$ 为 $1000 \Omega, R_{\mathrm{s}}$ 和 $I_{0}$ 则保持不变.

根据串联电阻 $R_{\mathrm{s}}$ 、并联电阻 $R_{\mathrm{sh}}$ 和二极管暗饱和 电流 $I_{0}$ 的定义 ${ }^{[26]}$ 可对模拟结果的合理性作出解释. $R_{\mathrm{s}}$ 表示太阳电池的内电阻. 它主要由金属电极与半导 体材料的接触电阻、半导体材料的体电阻和电极电阻 组成. $R_{\mathrm{s}}$ 越大意味着消耗在电池内电阻上的无用功率 越多, 电池效率越低. $R_{\mathrm{sh}}$ 用来表征太阳电池 $\mathrm{pn}$ 结漏 电(短路)造成的电学损失. 它主要由 pn 结边缘漏电 (短路)和 $\mathrm{pn}$ 结势垒区内杂质及缺陷引起的结区漏电 (短路)组成. $R_{\mathrm{sh}}$ 越大, 意味着 $\mathrm{pn}$ 结漏电越小, 电池效 率越高. $I_{0}$ 由电池各部分(基区、发射区和空间电荷区) 的复合电流组成. 由 $I_{0}$ 的表达式 ${ }^{[26]}$ 可知, 其大小主要 取决于基区和发射区的少子寿命以及 $\mathrm{pn}$ 结面积等. 对于浅结太阳电池, 发射区复合电流对 $I_{0}$ 的贡献占主 导地位，这是由发射区较重的表面和体内复合造成 的较短的少子寿命决定的. 由前面的讨论可知, 外延 晶体硅薄膜太阳电池的性能主要受到不足的少子扩 散长度(或少子寿命)的限制. 换句话说, 较大的电池 表面及体区复合(或较大的二极管暗饱和电流)是限 制电池效率的主要因素. 基于以上认识, 模拟给出的 结论“ $I_{0}$ 对电池效率的影响比 $R_{\mathrm{sh}}$ 和 $R_{\mathrm{S}}$ 对电池效率的 影响显著”就不难理解了. 

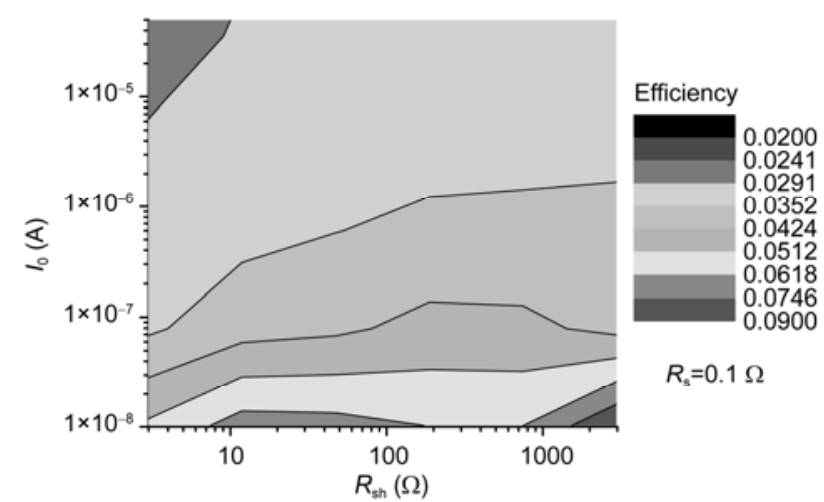

$R_{\mathrm{s}}=0.1 \Omega$

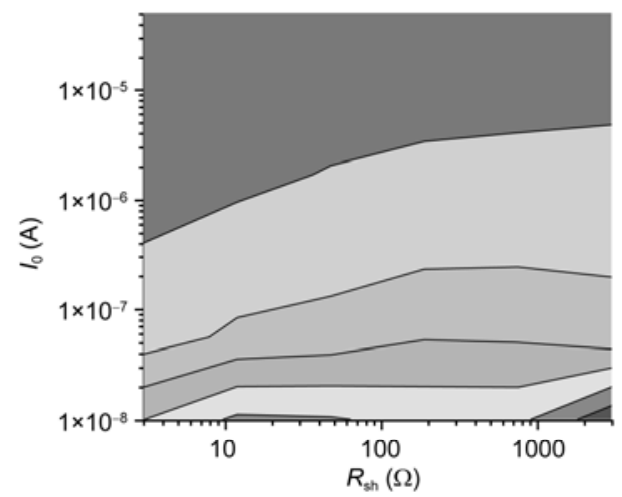

Efficiency

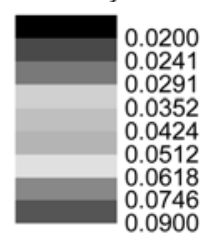

$R_{\mathrm{s}}=0.5 \Omega$

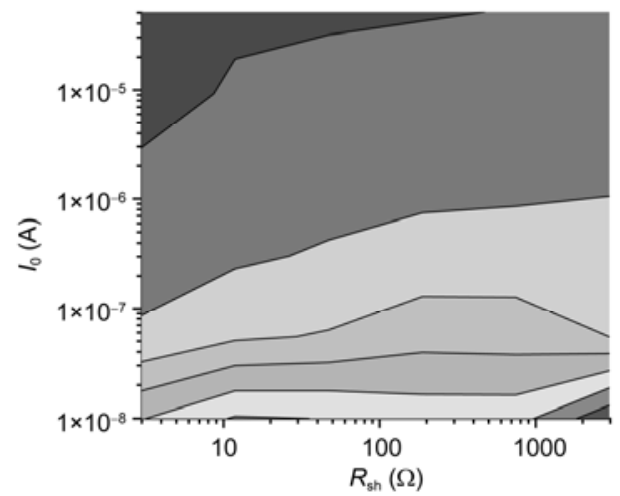

Efficiency

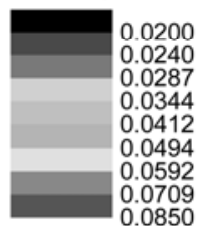

$R_{\mathrm{s}}=1 \Omega$

图 8 电池效率与二极管暗饱和电流 $\boldsymbol{I}_{\mathbf{0}}$ 和并联电阻 $\boldsymbol{R}_{\mathrm{sh}}$ 的关 系 (以串联电阻 $\boldsymbol{R}_{\mathrm{s}}$ 为参数)

经模拟优化的参数有: BSF 层厚度(取 $4 \mu \mathrm{m}$ )、 BSF 层掺杂浓度(取 $2 \times 10^{19} \mathrm{~cm}^{-3}$ )、基区掺杂浓度(取 $5 \times 10^{16} \mathrm{~cm}^{-3}$ )、发射区方块电阻(取 $75 \Omega / \square$ )、结深(取 $0.23 \mu \mathrm{m}$ ) 和并联电阻(取 $1000 \Omega$ ). 由以上优化后的参 数(其他参数与表 1 同) 定义的晶体硅薄膜太阳电池的 性能表现如下: 短路电流 $I_{\mathrm{sc}}=0.0309 \mathrm{~A}$, 开路电压 $V_{\mathrm{oc}}=0.3836 \mathrm{~V}$, 填充因子 $F F=0.75$, 效率 $\eta=8.9 \%$, 比 优化前的电池效率提高了 $7 \%$. 图 9 给出了参数优化 前后晶体硅薄膜太阳电池的 $I-V$ 特性及外量子效率模 拟曲线. 由图 9 可知, 参数优化后晶体硅薄膜太阳电
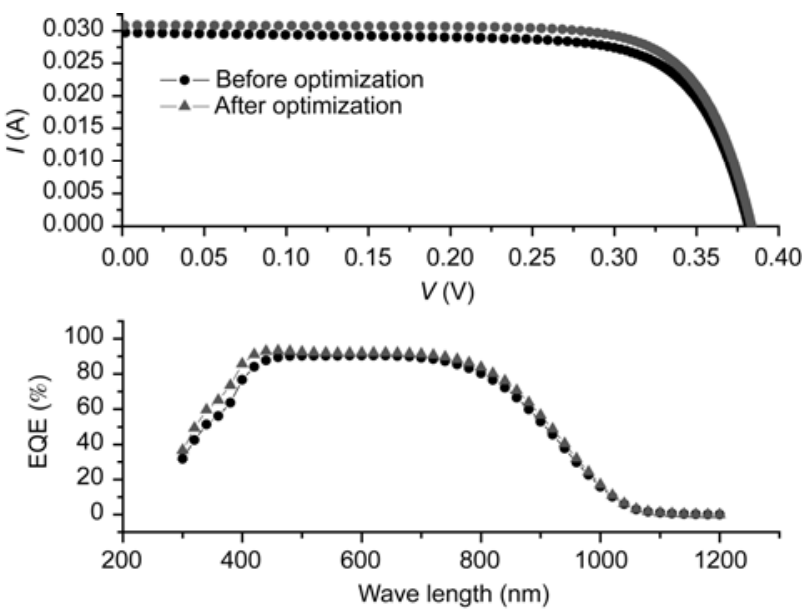

图 9 参数优化前后晶体硅薄膜太阳电池的 $I-V$ 特性及外量 子效率曲线

池的 $I-V$ 特性和光谱响应性能均得到不同程度的改善.

需要说明的是, 任何参数的改进都要受到实验 条件的限制. 我们所做的参数优化是利用现有实验 条件就可以实现的，所以效率提升的幅度有限. 另一 方面也说明表 1 所给出的参数设置已比较接近现有 工艺条件下的理想值. 如果不考虑实验条件的限制, 可采用各种先进的技术手段来提高电池的效率，我 们最需要改进的参数应该是少子扩散长度、二极管暗 饱和电流和正表面复合速度等. 然而这些参数的改 善需要使用额外的复杂技术，譬如采用区熔再结晶 技术来提高晶体硅活性层的晶体质量、对电池体区及 表面进行远距离等离子体氢针化和制备选择性发射 极等. 显然, 这些技术可以大幅提高外延晶体硅薄膜 太阳电池的效率.

\section{4 结论}

本文利用 PC1D 软件对外延晶体硅薄膜太阳电 池进行了器件模拟. 为了使模拟更接近真实的情况, 我们将外延晶体硅薄膜太阳电池的器件结构分成 4 个区，即祄底、BSF 层、过渡区和基区(通过在基区前 表面扩磷形成发射区). 在此基础上，我们依次对 BSF 层参数、基区参数和发射区参数进行了优化. 通 过模拟，我们发现相对于 BSF 层厚度，基区掺杂浓度 和发射区方块电阻而言, BSF 层掺杂浓度, 基区少子 扩散长度和结深对电池效率的影响更显著. 特别需 要强调的是, 基区厚度的选择必须要考虑基区少子 
扩散长度的值. 当基区少子扩散长度较小时, 基区的 最佳厚度应小于或等于基区少子扩散长度; 当基区 少子扩散长度较大时, 基区少子扩散长度应该至少 是最佳基区厚度的 2 倍. 此外, 我们还研究了晶体硅 活性层电学质量、电池表面钝化情况、电池内部复合 情况和 pn 结漏电情况对电池光电性能的影响. 结果 表明, 基区少子扩散长度对电池效率的影响远比正 表面复合速度对电池效率的影响显著. 在所研究的
正表面复合速度范围 $\left(S_{\mathrm{f}}=1 \times 10^{4} \sim 1 \times 10^{6} \mathrm{~cm} / \mathrm{s}\right)$, 当基区 少子扩散长度较大 $(\geqslant 65 \mu \mathrm{m})$ 时, 电池可获得理想的效 率, 且几乎不受正表面复合速度的影响.二极管暗饱 和电流对电池效率的影响远比并联电阻和串联电阻 对电池效率的影响显著. 当二极管暗饱和电流从 $5 \times 10^{-5} \mathrm{~A}$ 减小到 $1 \times 10^{-8} \mathrm{~A}$ 时, 在所研究的参数范围 (并联电阻从 $3 \Omega$ 变到 $3000 \Omega$, 串联电阻从 $0.1 \Omega$ 变到 $1 \Omega$ ), 平均来说电池效率从 3\%提高到 $6 \%$.

\section{参考文献}

1 Ulzhöfer C, Altermatt P P, Harder N P, et al. Loss analysis of emitter-wrap-through silicon solar cells by means of experiment and three-dimensional device modeling. J Appl Phys, 2010, 107: 104509

2 Rahmouni M, Datta A, Chatterjee P, et al. Carrier transport and sensitivity issues in heterojunction with intrinsic thin layer solar cells on N-type crystalline silicon: A computer simulation study. J Appl Phys, 2010, 107: 054521

3 Datta A, Damon-Lacoste J, Roca i Cabarrocas P, et al. Defect states on the surfaces of a P-type c-Si wafer and how they control the performance of a double heterojunction solar cell. Sol Energ Mat Sol C, 2008, 92: 1500-1507

4 Farrokh-Baroughi M, Sivoththaman S. Modelling of grain boundary effects in nanocrystalline/multicrystalline silicon heterojunction solar cells. Semicond Sci Tech, 2006, 21: 979-986

5 Harder N P, Mertens V, Brendel R. Numerical simulations of buried emitter back-junction solar cells. Prog Photovoltaics, 2009, 17: 253-263

6 Mader C, Müller J, Gatz S, et al. Rear-side point-contacts by inline thermal evaporation of aluminum. In: IEEE Electron Devices Society Staff, eds. The Conference Record of the 35th IEEE Photovoltaic Specialists Conference. Hawaii: Institute of Electrical and Electronics Engineers (IEEE), 2010. 1446-1449

7 Hilali M M, Nakayashiki K, Ebong A, et al. High-efficiency (19\%) screen-printed textured cells on low-resistivity float-zone silicon with high sheet-resistance emitters. Prog Photovoltaics, 2006, 14: 135-144

8 Kang M H, Hong J, Cooper I, et al. Reduction in light induced degradation (LID) in B-doped Cz-Si solar cells with SiCxNy antireflection (AR) coating. J Electrochem Soc, 2011, 158: H724-H726

9 Clugston D A, Basore P A. PC1D version 5: 32-bit solar cell modeling on personal computers. In: IEEE Electron Devices Society, eds. The Conference Record of the 26th IEEE Photovoltaic Specialists Conference. Anaheim: Institute of Electrical and Electronics Engineers (IEEE), 1997. 207-210

10 Rover D T, Basore P A, Thorson G M. Solar cell modeling on personal computers. In: IEEE Electron Devices Society Staff, eds. The Conference Record of the 18th IEEE Photovoltaic Specialists Conference. Las Vegas: Institute of Electrical and Electronics Engineers (IEEE), 1985. 703-709

11 Basore P A, Rover D T, Smith A W. PC-1D version 2: Enhanced numerical solar cell modeling. In: IEEE Electron Devices Society Staff, eds. The Conference Record of the 20th IEEE Photovoltaic Specialists Conference. Las Vegas: Institute of Electrical and Electronics Engineers (IEEE), 1988. 389-396

12 Basore P A. PC-1D version 3: Improved speed and convergence. In: IEEE Electron Devices Society Staff, eds. The Conference Record of the 22nd IEEE Photovoltaic Specialists Conference. New York: Institute of Electrical and Electronics Engineers (IEEE), 1991. 299-302

13 Basore P A, Clugston D A. PC1D version 4 for Windows: from analysis to design. In: IEEE Electron Devices Society, eds. The Conference Record of the 25th IEEE Photovoltaic Specialists Conference. Washington: Institute of Electrical and Electronics Engineers (IEEE), 1996. 377-381

14 Reber S, Hurrle A, Eyer A, et al. Crystalline silicon thin-film solar cells—recent results at Fraunhofer ISE. Sol Energy, 2004, 77: 865-875

15 Ai B, Shen H, Liang Z C, et al. Study on epitaxial silicon thin film solar cells on low cost silicon ribbon substrates. J Cryst Growth, 2005, 276: 83-91

16 Zhao Y W, Geng X H, Wang W J, et al. R\&D activities of silicon-based thin-film solar cells in China. Phys Status Solidi A, 2006, 203: 714-720 
17 Gordon I, Carnel L, Van Gestel D, et al. 8\% efficient thin-film polycrystalline-silicon solar cells based on aluminum-induced crystallization and thermal CVD. Prog Photovoltaics, 2007, 15: 575-586

18 Wang J H, Lien S Y, Chen C F, et al. Large-grain polycrystalline silicon solar cell on epitaxial thickening of AIC seed layer by Hot Wire CVD. IEEE Electr Device L, 2010, 31: 38-40

19 Perraki V. Modelling of recombination velocity and doping influence in epitaxial silicon solar cells. Sol Energ Mat Sol C, 2010, 94: $1597-1603$

20 Faller F R. Epitaxial Silicon Thin-film Solar Cells. Dissertation of Doctoral Degree. Freiburg: Albert Ludwigs University, 1998. 6-30

21 艾斌, 沈辉, 班群, 等. 外延晶体硅薄膜太阳电池的量子效率和特性研究. 中国科学 $\mathrm{E}$ 辑: 技术科学, 2004, 34: 1300-1312

22 励旭东. 低成本衬底上晶体硅薄膜太阳电池的研究. 博士学位论文. 北京: 北京师范大学, 2003. 55-59

23 艾斌. 颗粒硅带上外延制备多晶硅薄膜太阳电池及系统优化设计的研究. 博士学位论文. 北京: 中国科学院半导体研究所, 2003. 153-190

24 Ai B, Shen H, Liang Z C, et al. Electrical properties of B-doped polycrystalline silicon thin films prepared by rapid thermal chemical vapour deposition. Thin Solid Films, 2006, 497: 157-162

25 Green M A. Silicon Solar Cells: Advanced Principles \& Practice. Sydney: University of New South Wales, 1995. 333-336

26 Green M A. Solar Cells: Operating Principles, Technology and System Applications. Sydney: University of New South Wales, 1998. 76-96 